\title{
Primary Liposarcoma of Lung - A Rare Case Report
}

\author{
Amisha Gami, Nisha Khanna, Shailee Mehta', Dhaval Jetly \\ Departments of Oncopathology, and 'Pathology, Gujarat Cancer and Research Institute, Ahmedabad, Gujarat, India
}

\section{Abstract}

Liposarcoma of the lung is an extremely rare disease, with very few cases reported to date. We report a case of a primary pulmonary liposarcoma with pleural involvement in a 36-year-old male with peribronchial lymph node metastasis. Thoracotomic excision revealed a well-differentiated liposarcoma. Liposarcoma of lung is a rare tumor, which needs to be considered while looking at a biopsy, especially because it has a good survival when adequately excised. Lymph node metastasis, though rare can also occur.

Keywords: Liposarcoma, lung, lymph node metastasis

\section{INTRODUCTION}

Primary sarcoma of the lung is a relatively rare lung tumor, of which liposarcomas are extremely rare, with very few cases reported in literature. Liposarcomas are known to involve soft tissues, particularly thigh, retroperitoneum, etc., but thoracic and more so pulmonary primary liposarcomas are rare. ${ }^{[1]}$ As of 2012, 14 cases of primary pulmonary liposarcomas have been reported, ${ }^{[2]}$ lymph node metastases being even rarer.

We report a case of primary pulmonary liposarcoma in a 36-year-old male with lymph node metastases.

\section{Case Report}

A 36-year-old male presented to the Outpatient Facility of Gujarat Cancer Research Institute complaining of abdominal pain. He was investigated during which computerized tomography scan of thorax revealed a $12.9 \mathrm{~cm} \times 7.9 \mathrm{~cm} \times 7.3$ $\mathrm{cm}^{3}$ dense lesion in the right lower part of the thorax with a collapsed lower lobe of lung. A biopsy was performed which showed a spindle cell tumor.

Thoracotomic excision of the tumor was performed with excision of $6^{\text {th }}, 7^{\text {th }}$, and $8^{\text {th }}$ ribs along with diaphragm and lower lobe of the right lung. The specimen was sent for histopathological examination.

Gross examination revealed a fairly well circumscribed $13 \mathrm{~cm}$ mass involving the lung parenchyma with a yellow to

\begin{tabular}{|l|l|}
\hline \multicolumn{2}{|c|}{ Access this article online } \\
\hline Quick Response Code: & Website: \\
\hline
\end{tabular}

gray-white cut surface. The tumor was adherent to the pleura. However, the ribs appeared to be free of tumor.

Microscopic examination revealed a tumor comprised of predominantly of mature adipocytes separated into lobules by coarse and dense fibrosclerotic septa [Figure 1 and 2]. Interspersed were lipoblasts along with hibernomatous cells and inflammatory cells comprising lymphocytes, plasma cells, and foamy macrophages. Areas of infarct such as necrosis, classical multivacuolated lipoblasts, and multinucleate giant cells were seen. Lymphovascular emboli were evident. No areas of myxoid background or dedifferentiation were present. The pleura which were sent separately showed tumor infiltration. Moreover, two peribronchial lymph nodes showed metastatic tumor [Figure 3].

Differential diagnosis may include lipoma, thymolipoma, teratoma, lymphoma, and germ cell tumor based on the morphology and clinical setting.

Immunohistochemistry with monoclonal antibodies showed positive staining for vimentin and S-100 and was negative for Calretinin, WT1, CD34, and Bcl-2, aided in the final diagnosis of well-differentiated pulmonary liposarcoma with peribronchial lymph node metastases.

Address for correspondence: Dr. Shailee Mehta, 412, Department of Pathology, Gujarat Cancer and Research Institute, Civil Hospital Campus, Asarwa, Ahmedabad - 380 016, Gujarat, India. E-mail: shaileemehtaa@gmail.com

This is an open access journal, and articles are distributed under the terms of the Creative Commons Attribution-NonCommercial-ShareAlike 4.0 License, which allows others to remix, tweak, and build upon the work non-commercially, as long as appropriate credit is given and the new creations are licensed under the identical terms.

For reprints contact: reprints@medknow.com

How to cite this article: Gami A, Khanna N, Mehta S, Jetly D. Primary liposarcoma of lung - A rare case report. Indian J Respir Care 2020;9:100-2.

Received: 07-04-2019 Revised: 23-05-2019

Accepted: 07-10-2019 Published: 08-01-2020 
Gami, et al.: Primary liposarcoma of lung

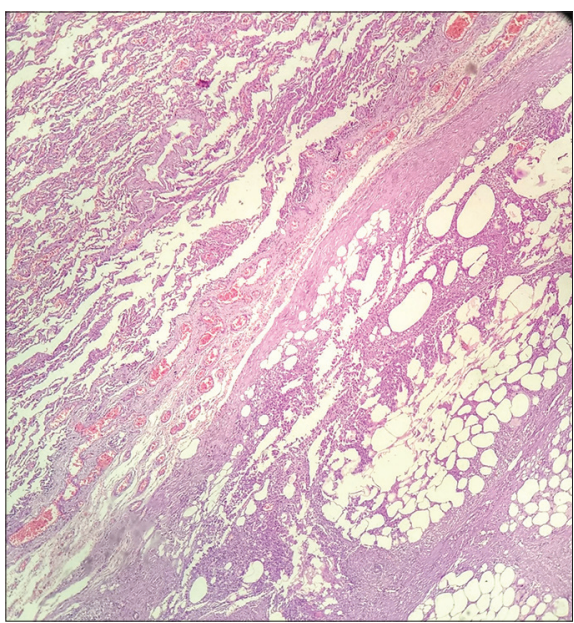

Figure 1: $\times 10$ view of a hematoxylin and eosin-stained slide shows an encapsulated tumor (bottom right) along with normal lung parenchyma (top left)

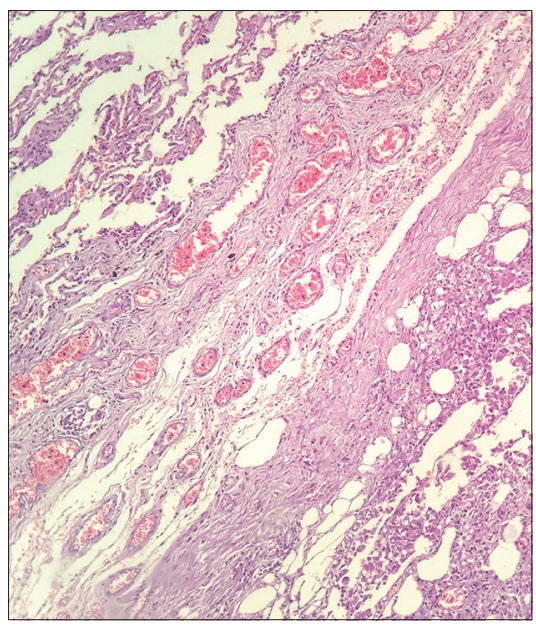

Figure 2: Further magnification showing tumor along with normal lung parenchyma

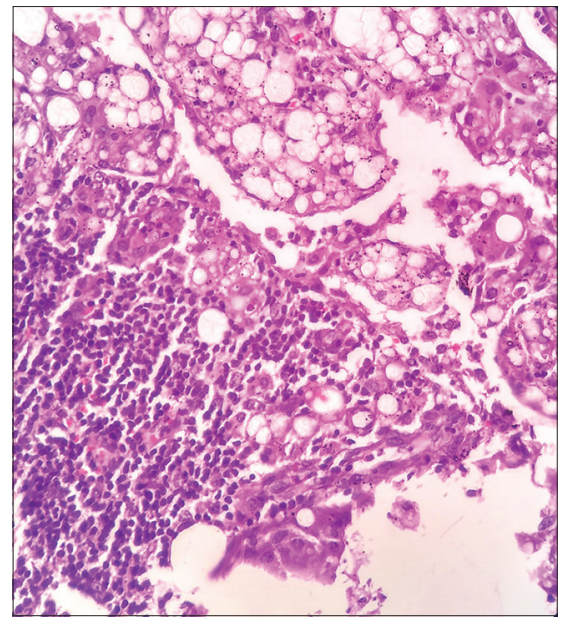

Figure 3: Lymph node involved by metastatic liposarcoma

The patient has been on regular follow-up postoperatively. He was given curative radiotherapy in view of lymph node metastasis followed by chemotherapy. He is doing well and has been disease-free for 9 months.

\section{Discussion}

This case is reported because of the rare site of a common tumor and with an unusual presentation. Lung sarcomas comprise about $3 \%$ of lung tumors. Moreover, lymph node metastasis in a pulmonary liposarcoma is an extremely rare phenomenon.

Liposarcomas are relatively common soft-tissue tumors, particularly occurring in the trunk, extremities, or retroperitoneum. Mediastinal liposarcomas are rare, accounting for $0.1 \%-0.75 \%$ of all mediastinal tumors, of which primary pulmonary liposarcomas are rarer. ${ }^{[1]}$ These are believed to originate from primitive mesenchymal cells rather than mature fat cells.

Thoracic liposarcomas have been reported to be either mediastinal or pulmonary. Mediastinal liposarcomas more commonly involve the anterior or posterior mediastinum. Pulmonary liposarcoma may primarily involve the lung or maybe entirely pleural in origin. In advanced cases, it may be difficult to separate pulmonary from pleural tumors. Pulmonary liposarcomas are usually parenchymal masses which do not show on bronchoscopy; however, there has been a case report of a smooth brownish polypoid mass on bronchoscopy ${ }^{[3]}$ and a near-total obstruction observed on bronchoscopy. ${ }^{[4]}$

Mediastinal liposarcomas usually present as large tumors that are slow growing with respiratory symptoms such as cough, chest pain, and dyspnea or weight loss. There are no characteristic symptoms which delay the diagnosis, particularly if the lungs are not imaged. About $10 \%-18 \%$ of cases do not produce any symptom, as is this case. ${ }^{[1]}$ This is believed to be due to the expansile rather than infiltrative nature of the neoplasm. In the mediastinum, they occur more commonly in anterior and posterior compartments. ${ }^{[4]}$

As is already known, all the histological variants, well-differentiated, myxoid/round cell, dedifferentiated, and pleomorphic types of liposarcomas, can occur in the lung as elsewhere, and histologically, well-differentiated tumors behave better than the dedifferentiated ones. Immunohistochemically, liposarcomas are known to stain for Vimentin, S-100, and MDM2 and CDK4.

Sarcomas usually do not metastasize to the lymph nodes, where none of the cases showed lymph node metastasis. ${ }^{[1]}$ Our case was even rare because of the presence of peribronchial lymph node metastases.

Surgery is the treatment of choice and patients who undergo a radical surgery with no residual disease are known to have the best survival. ${ }^{[2]}$ Chemotherapy and radiotherapy, although not very helpful have been used as adjuvants in inoperable patients or those with residual disease or metastasis but are not found to be very helpful. Doxorubicin seems to be the single most active agent and improved response rate is evident when this 
drug is combined with other agents. A newer drug, palbociclib, is under trial to be considered in additional therapy along with surgery. Radiofrequency ablation has also been demonstrated as an effective treatment modality. ${ }^{[5]}$

\section{Conclusion}

Mediastinal liposarcoma is a rare tumor. Radiologists and pathologists need to keep this entity in mind while making a preoperative diagnosis. Prognosis depends on the histological subtype, stage, and surgical resectability with wide safety margins. Due to high rates of recurrence, a comprehensive surgical approach is required with long-term postoperative follow-up evaluation.

\section{Declaration of patient consent}

The authors certify that they have obtained all appropriate patient consent forms. In the form the patient(s) has/have given his/her/their consent for his/her/their images and other clinical information to be reported in the journal. The patients understand that their names and initials will not be published and due efforts will be made to conceal their identity, but anonymity cannot be guaranteed.

\section{Financial support and sponsorship}

Nil.

\section{Conflicts of interest}

There are no conflicts of interest.

\section{RefERENCES}

1. Maezato K. A case of primary pulmonary fibrosarcoma: A review of the literature in Japan. Japan J Chest Dis 1978;37:713.

2. Zhao $\mathrm{C}$, Zhang F, Zhang X, Tu S, Wu Z, Li X, et al. Recurrent primary mediastinal liposarcoma: A case report. Oncol Lett 2016;11:3782-4.

3. Sawamura K, Hashimoto T, Nanjo S, Nakamura K, Iioka S, Mori T, et al. Primary liposarcoma of the lung: Report of a case. J Surg Oncol 1982;19:243-6.

4. Krygier G, Amado A, Salisbury S, Fernandez I, Maedo N, Vazquez T, et al. Primary lung liposarcoma. Lung Cancer 1997;17:271-5.

5. Shoji F, Taketomi A, Yano T, Maehara Y. Intraoperative radiofrequency ablation in an open thoracotomy setting for the new treatment of mediastinal liposarcoma: Report of a case. Surg Today 2011;41:992-4. 